\title{
Is tissue polypeptide antigen more accurate than serum CEA for diagnosing pancreatic cancer?
}

\author{
A PANUCCI, C FABRIS, G DEL FAVERO, D BASSO, F DI MARIO, \\ L MARCHIORO,* A PICCOLI, M LISE, $\dagger$ A BURLINA,* R NACCARATO \\ From the ${ }^{*}$ Laboratorio di Chimica e Microscopia Clinica, Ospedale Civile di Padova, Italy, and the Istituti \\ di Medicina Interna (Cattedra di Malattie Apparato Digerente), Patologia Chirurgica I, Università degli \\ Studi di Padova, Italy
}

SUMMARY Tissue polypeptide antigen (TPA) and carcinoembryonic antigen (CEA) were determined in the sera of 36 control subjects, 30 patients with pancreatic cancer, 35 with chronic pancreatitis and 25 with non-pancreatic digestive disease to evaluate their role in detecting pancreatic malignancy. Abnormal values of TPA and CEA were found in 28 and 19 of 30 patients with pancreatic cancer, and in four and seven of 35 patients with chronic pancreatitis, respectively. Raised titres of TPA were observed more often than equivalent serum CEA in simulated pancreatic diseases. The receiver-operating (ROC) characteristic curves showed that TPA was more discriminating than CEA in detecting pancreatic cancer. Specificity was enhanced when both titres were abnormally high and sensitivity when one titre was raised, but the diagnostic accuracy of TPA alone has not improved, which satisfactorily discriminates pancreatic cancer from chronic pancreatitis.

Carcinoembryonic antigen (serum CEA) is a glycoprotein with a molecular weight of 180000 , comprising $60 \%$ carbohydrate. ${ }^{1-3}$ It exhibits an extensive heterogeneity with the carbohydrate chains, while the composition of amino acid remains remarkably constant. $^{23}$ Increased serum CEA concentrations have been described in various neoplastic diseases, ${ }^{45}$ including pancreatic cancer. ${ }^{6-9}$ Abnormal results have also been reported, however, in inflammatory conditions such as chronic pancreatitis. ${ }^{46810}$ Serum CEA has also been suggested as an indicator of tumour metastasis. ${ }^{1112}$

Tissue polypeptide antigen (TPA) is an unconjugated membrane protein without sugars, lipids, or prosthetic groups. Antibodies raised against TPA react immunologically with different proteins with molecular weights ranging from 20000 to 45000 and can be separated from each other. ${ }^{13-15}$ Increased TPA serum concentrations have been found not only in several neoplastic diseases but also in nonmalignant pathological conditions. ${ }^{15-17}$ High TPA values have almost invariably been observed in pancreatic cancer ${ }^{1618}$ and only occasionally in chronic pancreatitis. TPA is generally considered to be an indicator of tissue proliferation. ${ }^{13}$

The aim of this study was to evaluate CEA and TPA separately and in combination for their use-

Accepted for publication 19 August 1985 fulness in detecting pancreatic cancer.

\section{Material and methods}

One hundred and twenty six subjects were studied. Thirty six were control subjects ( 24 men, 12 women, age range 37-66 years), all healthy members of the medical staff or blood donors. Thirty patients had pancreatic cancer of duct cell origin ( 21 men, nine women, age range 43-71 years), which was histologically confirmed in all cases by means of biopsy taken during operation or at necropsy. ${ }^{19}$ Staging of the disease was: T1N0M0 (three cases), T2N1M0 (six), T2N1M1 (10), and T3N1M1 (11). Thirty five patients had chronic pancreatitis (11 calcified chronic pancreatitis) (31 men, four women, age range 23-68 years); the diagnosis was made clinically and using the positive results of at least two of the following examinations: plain abdomen radiography $\mathrm{X}$-ray for pancreatic calcifications, pancreatic ultrasonography, computed axial tomography and endoscopic retrograde pancreatography. The diagnosis was always histologically confirmed by means of multiple specimens taken intraoperatively. Twenty five patients were affected by pancreatic non-digestive diseases of a nonneoplastic nature (11 men, 14 women, age range 37-81 years). Diagnosis was based on the clinical picture and results of specific radiological and histological procedures: liver cirrhosis (six cases); gallstones (four); common duct stones (three); chronic gastritis (three); 
Table 1 Mean serum CEA and TPA concentrations (SEM)

\begin{tabular}{|c|c|c|c|}
\hline & $\begin{array}{l}\text { No of } \\
\text { cases }\end{array}$ & ${ }_{\bar{x}}^{C E A(\mu g / l)}$ & $\underset{\bar{x}}{T P A}(U / l)$ \\
\hline \multirow{3}{*}{$\begin{array}{l}\text { Control subjects } \\
\text { Patients with: } \\
\text { Pancreatic cancer } \\
\text { Chronic pancreatitis } \\
\text { Simulated pancreatic } \\
\text { diseases }\end{array}$} & 36 & $1.98^{*}(0 \cdot 10)$ & $60 \cdot 7 *(3.5)$ \\
\hline & $\begin{array}{l}30 \\
35\end{array}$ & $\begin{array}{r}10.57(3.46) \\
2.59 *(0.13)\end{array}$ & $\begin{array}{r}519.2 \quad(97.2) \\
71.6^{*}\end{array}$ \\
\hline & 25 & $2 \cdot 61 \dagger(0 \cdot 16)$ & $131 \cdot 7 *(15.9)$ \\
\hline Total & 126 & & \\
\hline & & $\begin{array}{l}F=5.99 \\
p<0.01\end{array}$ & $\begin{array}{l}F=21.4 \\
p<0.01\end{array}$ \\
\hline
\end{tabular}

Scheffe's method for multiple comparisons:

*p $<0.01$ (pancreatic cancer)

tp $<0.05$ (pancreatic cancer)

Table 2 Sensitivity, specificity, and diagnostic accuracy expressed as a percentage (Youden index) of CEA and TPA for diagnosing panicreatic cancer*

\begin{tabular}{lllll}
\hline & CEA & TPA & $\begin{array}{l}\text { CEA and } \\
\text { TPA } \dagger\end{array}$ & $\begin{array}{l}\text { CEA or } \\
\text { TPA }\end{array}$ \\
\hline Sensitivity & 63.3 & 93.3 & 53.3 & 100 \\
Specificity & 81.7 & 70.0 & 91.7 & 60.0 \\
Accuracy & 45.0 & 63.3 & 45.0 & 60.0 \\
\hline
\end{tabular}

*Cut off values for CEA and TPA were $3.14 \mu \mathrm{g} / 1$ and $102.9 \mathrm{U} / \mathrm{l}$, respectively.

tBoth variables yielding abnormal results.

fOne of the two variables yielding abnormal results.

irritable colon (three); duodenal ulcer (two); benign stenosis of the papilla of Vater (two); retroperitoneal fibrosis (one); and primary biliary cirrhosis (one).

Serum CEA and TPA were determined using radioimmunoassay techniques using commercial kits (Eiken Chemical Co and Prolifigen, AB Sangtec Medical, Bromma, Sweden, respectively). The statistical evaluation of the data was done analysing variance

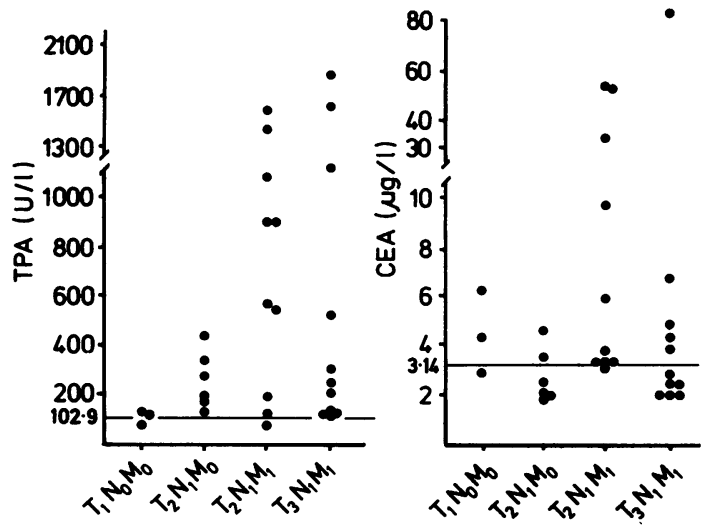

Fig. 1 Values of TPA and CEA in patients with pancreatic cancer related to stage of disease. Continuous lines represent upper normal limits (mean (2SD), of control subjects: $60.7(42.2) U / 1$ and $1.98(1.16) \mu \mathrm{g} / \mathrm{l}$ for TPA and $C E A$, respectively). $T N M=$ Numbers of tumours, nodes, and metastases.
(Anova one way), Scheffé's method for multiple com parisons, ${ }^{20}$ the $\chi^{2}$ test, the Youden index, ${ }^{21}$ and receiver-operating characteristic (ROC) curves. $^{22} \stackrel{\overline{9}}{\stackrel{5}{9}}$

\section{Results}

Table 1 shows the mean values, standard errors, and statistical evaluation of the data. A significantlyo increased incidence of abnormal CEA and TPA con-s centrations was detected in patients with pancreatic $\vec{\circ}$ cancer, taking the variables independently $\left(\chi^{2}=\overrightarrow{\vec{H}}\right.$ $31.97, \mathrm{p}<0.0005 ; \chi^{2}=76.09, \mathrm{p}<0.0005$, respectively) and in combination (either or botho abnormal; $\chi^{2}=64.47, p<0.0005 ; \chi^{2}=41.05, p<i$ 0.0005 , respectively). Fig. 1 illustrates the values of CEA and TPA in patients with pancreatic cancer according to the stage of the disease. Table 2 shows the results of the Youden index.

A significant linear correlation was noticed betweenserum CEA and TPA concentrations $(r=0.3845$, $\mathrm{p}<0.001$ ). Fig. 2 shows the ROC curves of the two variables used for diagnosing pancreatic cancer.

\section{Discussion}

Published reports on the determination of TPA foro diagnosing pancreatic cancer are few. Although TPA has generally been described as having a good sensi-o tivity, its value in discriminating pancreatic cancepo from chronic pancreatitis has not been established. In our study the serum TPA concentration was raised in $\overrightarrow{\vec{\sigma}}$ 28 of 30 patients with pancreatic cancer, confirming 3 the good sensitivity previously described in a preliminary study. ${ }^{18}$ Only four of 35 patients with? chronic pancreatitis had raised concentrations, which

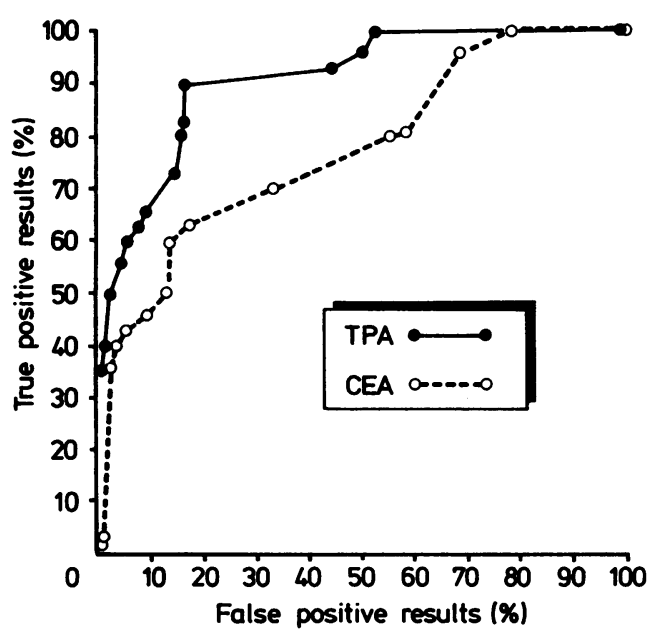

Fig. 2 Receiver-operating characteristic curves of CEA and TPA in the diagnosis of pancreatic cancer. 
were only slightly above normal in two. This indicates that TPA has a satisfactory specificity. Nevertheless, abnormal values in this test were often found in inflammatory diseases of the liver or the biliary tract, thus limiting the usefulness of the determination of TPA for assessing pancreatic cancer.

Serum CEA has been extensively investigated in patients with various malignant diseases. Its sensitivity and specificity in diagnosing pancreatic cancer were not entirely satisfactory according to previous observations ${ }^{82324}$; only 19 of our 30 patients with pancreatic neoplasm had raised CEA values. There were seven false positive results among patients with chronic pancreatitis. Abnormal results in digestive disease simulating pancreatic diseases, however, were found less often than when TPA was used.

Considering the results of the Youden index, TPA showed the highest sensitivity $(93 \%)$ and CEA the highest specificity (82\%); the diagnostic accuracy was acceptable only for TPA $(63 \%)$. The data were confirmed by the ROC curves: TPA was more discriminating than CEA in diagnosing pancreatic cancer for any serum value.

When patients with pancreatic cancer were divided according to the stage of the disease, no clear correlation was detected between metastasis and the serum values of either antigen. Although the highest values were observed in patients with metastatic pancreatic cancer, normal or slightly raised concentrations were also found. Thus these antigens do not provide definitive information on the stage of the tumour.

A good correlation was found between the two indexes, reflecting similar behaviour at least in part. CEA and TPA were tested in combination in an attempt to improve their diagnostic usefulness. Although an increase in specificity was obtained when both variables yielded abnormal results, and a corresponding increase in sensitivity when one variable yielded abnormal results, the overall accuracy has not improved.

In conclusion, TPA seems to be a sensitive index in diagnosing pancreatic cancer, more accurate than CEA and it satisfactorily discriminates pancreatic cancer from chronic pancreatitis, although not from non-pancreatic digestive diseases. Combining CEA with TPA does not substantially improve the results given by TPA alone.

This study was supported in part by a grant from the Italian National Research Council, Special Project Oncology, contract No 84.00725.44.

\section{References}

\footnotetext{
${ }^{1}$ Krantz MJ, Laferté S, Ariel N. Radioimmunoassay of carcinoembryonic antigen. Methods Enzymol 1982;84:32-48.

${ }^{2}$ Wagener C, Breuer H. Biochemical and immunochemical aspects of
}

carcinoembryonic antigen (CEA) and CEA related antigens: current status and future perspectives. J Clin Chem Clin Biochem 1982;20:705-12.

${ }^{3}$ Rogers GT. Carcinoembryonic antigen and related glycoproteins: molecular aspects and specificity. Biochim Biophys Acta 1983; 695:227-49.

${ }^{4}$ Begent RHJ. The value of carcinoembryonic antigen measurement in clinical practice. Ann Clin Biochem 1984;21:231-8.

${ }^{5}$ Martin EW, Kibbey WE, Di Vecchia L, Anderson G, Catalano P, Minton JP. Carcinoembryonic antigen: clinical and historical aspects. Cancer 1976;37:62-81.

${ }^{6}$ Yamauchi T, Funakoshi A, Wakasugi H, Hayakawa A, Ibayashi $H$. Clinical studies on carcinoembryonic antigen in pancreatic cancer. Gastroenterol Jpn 1979;14:122-8.

${ }^{7}$ Ona FV, Zamcheck N, Dhar P, Moore T, Kupchik HZ. Carcinoembryonic antigen (CEA) in the diagnosis of pancreatic cancer. Cancer 1973;31:324-7.

${ }^{8}$ Kalser MH, Barkin JS, Redlhammer D, Heal A. Circulating carcinoembryonic antigen in pancreatic carcinoma. Cancer 1978;42:1468-71.

${ }^{9}$ Medical Research Council Tumour Products Committee: clinical subgroup. The diagnostic value of plasma carcinoembryonic antigen (CEA) in pancreatic disease. Br J Cancer 1980;41:976-9.

${ }^{10}$ Delwiche R, Zamcheck N, Marcon N. Carcinoembryonic antigen in pancreatitis. Cancer 1973;31:328-30.

${ }^{11}$ National Institute of Health Consensus Development Conference statement. Carcinoembryonic antigen: its role as a marker in the management of cancer. Cancer Res 1981;41:2017-8.

${ }^{12}$ Goldenberg DM, Neville AM, Carter AC, et al. CEA (carcinoembryonic antigen): its role as a marker in the management of cancer. J Cancer Res Clin Oncol 1981;101:239-42.

${ }^{13}$ Björklund B, Björklund V, Lundström R, Eklund G. Tissue polypeptide antigen (TPA) in human cancer defense responses. In: Friedman H, Escobar MR, Reichard SM, eds. The reticuloendothelial system in health and disease: immunologic and pathologic aspects. New York: Plenum Publishing, 1976.

${ }^{14}$ Björklund B. Tissue polypeptide antigen (TPA): biology, biochemistry, improved assay methodology, clinical significance in cancer and other conditions, and future outlook. Antibiot Chemother 1978;22:16-31.

${ }^{15}$ Björklund B. On the nature and clinical use of tissue polypeptide antigen (TPA). Tumor Diagnostik 1980;1:9-20.

${ }^{16}$ Menendez-Botet CJ, Oettgen HF, Pinsky CM, Schwartz MK. A preliminary evaluation of tissue polypeptide antigen in serum or urine (or both) of patients with cancer or benign neoplasm. Clin Chem 1978;24:868-72.

${ }^{17}$ Mross K, Mross B, Wolfrum DI, Rauschecker H. Determination of TPA levels in breast cancer and controls. Klin Wochenschr 1983;61:461-8.

${ }^{18}$ Panucci A, De Silvestro G, Fabris C, et al. Serum tissue polypeptide antigen in chronic pancreatic disease. Does hepatic damage have any influence? Ric Clin Lab 1984;14:425-9.

${ }^{19}$ Cubilla AL, Fitzgerald PJ. Pancreas cancer 1. Duct adenocarcinoma. Pathol Annu 1978;13:241-89.

${ }^{20}$ Guenther WC. Analysis of variance. Englewood Cliffs: Prentice Hall, 1964.

${ }^{21}$ Armitage P. Statistical methods in medical research. Oxford: Blackwell Scientific Publications, 1971.

${ }^{22}$ Weinstein MC, Fineberg HV. Clinical decision analysis. Philadelphia: MB Saunders, 1980.

${ }^{23}$ Hölbling N, Funovics J, Euler J, Karner J, Zöch G, Sauermann G. Zur Anwendbarkeit der Poly-C-spezifischen Serum Ribonuklease und des CEA in der Diagnose des Pankreaskarzinoms. Klin Wochenschr 1981;59:1201-7.

${ }^{24}$ Fabris C, Farini R, Piccoli A, et al. CEA and ferritin in chronic pancreatic disease: a comparative evaluation. Hepa togastroenterology 1985;32:146-8.

Requests for reprints to: Professor Remo Naccarato, Istituto di Medicina Interna, Cattedra di Malattie Apparato Digerente, Policlinico Universitario, 35100 Padova, Italia. 